\title{
A MORTE NO HOSPITAL E SEU SIGNIFICADO PARA OS PROFISSIONAIS*
}

\author{
Thelma Spindola** \\ Maria do Carmo dos Santos Macedo***
}

\begin{abstract}
RESUMO: O presente estudo pretende desvelar o significado do morrer dos pacientes aos olhos de profissionais de saúde. Para tanto, recorremos à metodologia qualitativa com abordagem fenomenológica que permite a compreensão do fenômeno a partir das falas dos profissionais de saúde. Os depoimentos foram coletados na Clínica Médica e de Doenças Infecto-Parasitárias do Hospital Universitário Gaffrée e Guinle, no Rio de Janeiro. A análise das convergências possibilitam a identificação de algumas unidades de significação que podem servir como facilitadores para os profissionais no enfrentamento do morrer dos pacientes.
\end{abstract}

\begin{abstract}
This paper intends to uncover the significance of the pacients' death in the eyes of health professionals. Therefore, we resorted to qualitative methodology with phenomenological approaching, that allows the understanding of phenomenon based in opinions of health professionals. The depositions were collected at Medic and Infective Parasitic Clinics at Gaffrée and Guinle University Hospital, Rio de Janeiro. The analysis of convergences facilitates the identification of some signification which can serve as facilitaters to professionals in the confront to pacients' death.
\end{abstract}

UNITERMOS: Morte - Significado - Profissionais de Saúde.

\section{INTRODUÇÃO}

O tema morte vem sendo discutido ao longo dos anos. Ultimamente tem-se observado um aumento crescente de estudos relativos a esta temática. Apesar de compor o ciclo biológico dos seres vivos (nascer, crescer e morrer), o homem moderno tem procurado manter-se afastado de sua evidência, em razão das mudanças de costumes que se processaram com o correr dos tempos.

Nos dias atuais, doença e morte residem no hospital deixando de ocupar, como outrora, o aconchego do lar. Graças à valorização do homem enquanto ser produtivo, exaltado pelo regime capitalista, só merece consideração aquele que contribui com sua força de trabalho. Assim, o sentimento de união e coletividade, comuns no passado, acaba sendo penalizado e substituído pelo individualismo.

Em nossos dias, a partir do instante em que o homem adoece e perde sua capacidade de produzir, passa a ser um personagem indesejável, sendo necessário o seu confinamento em algum local. O hospital apresenta-se então, como o lugar ideal para realizar este cuidado, antes vivido junto aos familiares e amigos em seu lar. Surgem profissionais qualificados para o desempenho destas funções, ou seja cuidar do doente para que recupere seu equilíbrio geral e retome às suas atividades. Esta perspectiva é confirmada por PITTA(10) esclarecendo que

\footnotetext{
- Trabalho apresentado como Tema Livre no $45^{\circ}$ Congresso Brasileiro de Enfermagem. Olinda-Recife, 28 de novembro a 3 de dezembro de 1993.

** Enfermeira, Me stre em Enfermagem pela UNI-RIO, Coordenadora da Assessoria de Estágios e Atividades Cientificas do Hospital Universitário Gaffrée e Guinle, Professora Auxiliar contratada no Departamento de Enfermagem Fundamental da Faculdade de Enfermagem da UERJ.

*** Enfermeira, Mestre em Enfermagem pela UNI-RIO, Supervisora do Hospital Universitário Gaffrée e Guinle, Professora Assistente no Departamento de Fundamentos de Enfermagem da Faculdade de Enfermagem da UERJ.
} 
adoecer, nesta sociedade, é vergonhoso, é deixar de produzir, de ser. O doente deve ser excluído, ocultado para não impedir que familiares e amigos produzam. $O$ papel do hospital seria 0 de recuperá-lo para devolvê-lo à sua situação anterior.

Distinto dos primórdios dos séculos, onde a morte era vivenciada por toda a comunidade, 0 homem moderno acostumou-se a visualizá-la bem distante de si, atingindo apenas os mais velhos em decorrência dos avanços tecnológicos e ao aumento da expectativa de vida. Criamse peritos para cuidarem dos doentes agonizantes, como o médico e os profissionais de enfermagem, e dos cadáveres como: o agente funerário e o coveiro. A comunidade e os familiares acabam sendo poupados e, em ambientes especiais, estes profissionais assumem seus papéis permitindo uma participação mais periférica no morrer e impedindo, desta maneira, o desgaste do envolvimento total. A cerimonia da morte fica assim entregue a profissionais, o que despersonaliza, neutraliza, especializa e fragmenta 0 assunto(5:165-169).

Num passado recente, o homem enfrentava a morte quase sempre em casa, junto aos seus familiares e amigos, recebendo carinho, atenção e tendo seus últimos desejos atendidos. Era dificil encaminhar o doente para morrer no hospital, onde o doente permanece isolado, distante dos seus entes, sentindo-se sozinho e abandonado. A estrutura familiar na sociedade capitalista não difere muito da situação do doente hospitalizado transformando-se em muitos casos, também, em um local de solidão e abandono. Todavia, no hospitak, o homem morre cercado de estranhos, de pessoas com as quais não tem afinidade, tomando-se $o$ leito $X$ ou a doença $Z^{(13)}$.

Dentre aqueles que trabalham na área da saúde, diretamente envolvidos com a situação de vida e morte em seu dia-a-dia, destacam-se o médico e os profissionais de enfermagem. $O$ médico, alvo de todas as expectativas da comunidade, exerce grande influência no clima geral de sentimentos e pensamentos sobre os demais homens, em especial seus pacientes e familiares. Sua relação com a morte, na maioria das vezes, é impessoal, fria e objetiva, em função de sua característica profissional. Dotados dè grande responsabilidade pela socieda- de, a morte não deixa de ser aquele inconveniente que os surpreende e derrota(5:177-181).

O enfermeiro e demais profissionais de enfermagem desempenham importante papel junto aos pacientes hospitalizados. Em virtude de conviverem um período maior com os mesmos, geralmente, iniciam os cuidados aos pacientes com fortes sentimentos, mantêm as sensações durante o decurso da doença e com o chegar da morte vêem-se impelidos a conter seus sentimentos, demonstrando fortaleza de ânimo(5:181189). Os componentes sócio-culturais destes profissionais interagem no seu enfrentamento do morrer porém, com frequência, é mencionado pelas demais pessoas a frieza e distanciamento destes para com esta problemática.

Em estudo recente com profissionais de enfermagem do CTI de um hospital geral público no Rio de Janeiro, obtivemos depoimentos onde foi citada a aparente insensibilidade destas pessoas diante do morrer dos pacientes a quem assistem, tendo sido revelado que empregavam este mecanismo de defesa para suportarem meIhor o seu cotidiano(14).

Sendo enfermeira de um hospital universitário e convivendo com situações de vida e morte, freqüentemente questionava como nós, profissionais de saúde, estávamos participando do morrer dos pacientes? Em nossa vivência em $\mathrm{CTI}$, o contato com o morrer era constante e sempre, nestes momentos, ficava com uma sensação de vazio, de fracasso... A abordagem deste tema sempre nos inquietava e sempre quizemos entender o que os demais profissionais sentiam a respeito. Em um plantão de final de semana, ao assistirmos o morrer de um jovem paciente de 24 anos com tuberculose pulmonar, e presenciarmos o desamparo daqueles que 0 assistiam, começamos a questionar qual seria 0 nosso papel e como estávamos reagindo diante do morrer dos pacientes. Partindo desta inquietação, juntamente com outra enfermeira, decidimos investigar o significado do morrer para profissionais como o médico, o enfermeiro e o auxiliar de enfermagem que, em seu dia-a-dia, convivem com esta questão.

Desta forma, o presente estudo pretende compreender o significado do morrer para os profissionais de saúde, acreditando que este desvelamento nos fomecerá subsídios que possibilitarão a compreensão melhor desse fenômeno. 


\section{O TEMA MORTE E SUA TRAJETÓRIA ATRAVÉS DOS TEMPOS}

A morte é um desafio para os homens. A falta de explicaçōes sobre o que acontece após a morte sempre despertou interesse e, ao mesmo tempo, grande temor entre os homens em razão de nossa dificuldade em lidar com este tema.

No entender de KASTENBAUM e AISEMBERG(5:149-151) existem algumas condições básicas de existência que influenciam sobre como encarar a morte, sendo comuns entre as sociedades, desde as primitivas até algumas do começo de nosso século, tais como:

- expectativa de vida limitada;

- ver-se em presença da morte;

- controle reduzido sobre as forças da natureza;

- o status do indivíduo.

De uma maneira geral, as sociedades desenvolveram costumes ou rituais de como conviverem com a morte. Durante muitos séculos foi considerada como um acontecimento natural, esperado, sendo possível ao homem morrer em seu leito, cercado de familiares e amigos, mantendo um controle sobre suas últimas vontades. Temia-se a morte inesperada porque privava 0 homem de preparar-se para este momento(3).

Desde a Antigüidade, os egípcios possuiam um sistema mortuário explícito e detalhado em seu Livro dos Mortos, no qual eram traçadas ações individuais a serem desempenhadas diante da morte. Assim, acreditavam no controle mágico sobre as poderosas forças da morte e a pós-vida estimulando-se com esta crença. Neste período, a morte era visualizada como algo agressivo que gerava a sensação de perda. Os homens apoiavam-se em crenças e mitos com o intuito de superá-la ou aceitá-la com mais resignação(5:149-154).

No entender de ARIES(1:103-310), dos séculos V e VI até o século XII, a morte fazia parte do cotidiano dos homens. Não havia individualização da morte e quando alguém morria era enterrado em valas ou fossas comuns. Todos os corpos ficavam amontoados sem a preocupação de individualização, ou seja, de dar um túmulo especial para cada um. Apenas os sacerdotes e reis, grandes personalidades, possuiam um local reservado em igrejas ou catedrais. A morte, nesta época, era encarada com naturalidade, não sendo interpretada de maneira dramática.

Do século XII ao século XVIII, ARIES(1:353442,2:81-92) cita o aparecimento do capitalismo europeu na Europa Ocidental, e com ele, a questão do individualismo. Começam a ocorrer transformações e a morte passa, então, a ser personalizada, surgindo inscrições em túmulos ou placas no chão. Entretanto, ainda não havia a noção de sepultura individual. Nesse periodo, a morte era desejada, solicitada em preces a Deus e aos santos, pedindo que se morresse de doença, cercado de familiares e amigos. Temia-se a morte inesperada, acidental ou por epidemias, sendo esta considerada um castigo de Deus. $\mathrm{Na}$ morte esperada, o próprio indivíduo preparava sua morte, procurava confessar-se, eliminando suas culpas, dizia seus últimos desejos e partiIhava seus bens entre seus familiares. A salvação da alma era a grande preocupação, sendo ao corpo dada pouca importância, o fundamental era a vida após a morte, conforme preconizam as idéias da Igreja.

No início do Cristianismo, a morte era considerado um fenômeno de perda, mas acreditavase na vida após a morte. Nesse momento, apesar desta crença, já se inicia o sentido do individualismo, começando a se desejar o adiamento da morte.

No século XVIII, decorrentes da Revolução Industrial, surgem mudançąs essenciais a nível econômico, social e político na Europa Ocidental. Realiza-se a urbanização, aparecendo as cidades e os operários, sendo exaltado o indivíduo. A morte passa então, a ser dramatizada, começando os períodos de luto, os enterros e as cenas das choradeiras. Nesse momento, com a ampliação das populaçỏes, surgem os cemitérios públicos, em decorrência do sanitarismo e pelas mudanças na forma de pensar. O cemitério assume a característica de um local sagrado e de reverência onde residem os mortos ${ }^{(1: 518-}$ 606, 2:81-92).

Das décadas de 30-40 deste século aos nossos dias, as sociedades mais avançadas transformaram-se e, graças à industrialização e à tecnologia, os homens passaram a controlar os fenômenos da vida e morte, através de mecanismos que visam prolongar a vida ou impedir a ocorrência da morte. Através da utilizaçãoo de modemos recursos, aumenta a expectativa de 
vida e, em consequência, diminui o convívio do homem com a morte, que passa a ser, então, indesejável, devendo ser ocultada, escondida. Surgem instituições para impedir o convivio com a morte, deslocando-a das casas para os hospitais.

Assim, a morte passa de algo esperado e cultuado a um fenômeno indesejável, devendo ser escondida. $O$ enfrentamento da morte, com o passar dos anos, modificou-se, deixando de ser um cerimonial cultuado entre familiares e amigos, para ser vivenciado ao lado de estranhos.

Nos dias atuais, doença e morte são uma realidade das instituições de saúde. Estas, inseridas no sistema para o qual foram preparadas, ficam alicerçadas a uma estrutura muitas vezes desumana, separando o homem do contexto em que ele vive, levando-o a encontrar dificuldades no adoecer e morrer.

\section{METODOLOGIA}

O estudo foi realizado segundo a metodologia qualitativa, utilizando a investigação fenomenológica, com a finalidade de compreender o significado do morrer de um paciente aos olhos dos profissionais de saúde, ou seja o médico, o enfermeiro e 0 auxiliar de enfermagem.

Conduzir uma investigação no referencial fenomenológico consiste em estudar o fenômeno situado tal como ele se apresenta aos olhos de quem experiencia a situação. A fenomenologia, preocupando-se com a essência do fenômeno, volta-se para a vivência do vivido e os significados atribuidos pelo sujeito que vive a experiência.

Nessa perspectiva, o significado do morrer de um paciente deverá ser buscado nas pessoas que o assistem, ou seja, os profissionais de saúde, por serem eles que vivenciam esse assistir e, através de seus depoimentos, poderemos chegar à essência do fenômeno.

Para que a compreensão do fenômeno situado assistir o morrer do paciente no contexto hospitalar possa ser desvelado, é necessário buscar nas falas daqueles que vivenciam esta experiência o significado deste momento. Para tanto, elaboramos a questão orientadora: Para vocé, o que significa o morrer de um paciente? - que facilitaria o seu dizer e, por conseguinte, a elaboração da descrição.

\subsection{O local e os sujeitos da pesquisa}

O estudo foi realizado no Hospital Universitário Gaffrée e Guinle no município do Rio de Janeiro.

Os depoimentos foram coletados no período de janeiro a março de 1993 e abrangem profissionais de saúde como: médicos, enfermeiros e auxiliares de enfermagem, lotados na Clínica Médica e de Doenças Infecto-Parasitárias (DIP), após a autorização da direção do Hospital e chefia da Divisão de Enfermagem para sua realização.

\subsection{Coleta dos depoimentos}

Enquanto enfermeiras na Instituição onde o estudo se realizou e responsáveis, respectivamente, pela Educação Continuada e Supervisão de Enfermagem, temos livre acesso aos diversos profissionais de saúde.

Em conversas informais, expusemos nossas inquietações e interesse na realização de um estudo com esta temática. Esclarecemos que gostariamos de entender este fenômeno e questionamos se estavam dispostos a participar. Explicamos que a participação seria voluntária e que o depoimento teria um caráter confidencial não havendo necessidade de identificação. Todos aqueles que abordamos mostraram-se interessados em colaborar.

Dada a complexidade do tema, achamos que seria necessário conceder um período maior para que a pessoa refletisse e respondesse. Assim, entregamos uma folha de papel onde havia a questão orientadora: Para vocé, o que significa o morrer de um paciente? Deixávamos com o profissional e solicitávamos que nos devolvesse quando tivesse respondido.

Dos profissionais envolvidos na pesquisa, alguns não devolveram alegando esquecimento ou falta de tempo. Assim, foram coletados 25 (vinte e cinco) depoimentos que se encontram à disposição, com as autoras.

\section{ANÁLISE COMPREENSIVA DOS DEPOIMENTOS}

Buscamos na leitura atentiva dos depoimen- 
tos os aspectos convergentes destas falas, ou seja, aquilo que se apresentava com a característica de repetitividade. Esse invariante que conduz à essência do pensar fenomenológico possibilitou a construção das unidades de significação e a compreensão da estrutura do fenômeno, situado conforme preconizam MARTINS e BICUDO(8) e MARTINS et al(9).

Desta forma, a análise dos depoimentos dos profissionais de saúde nos permitiu alcançar as unidades de significação que expressam a essência do assistir o morrer do paciente.

A análise compreensiva dos depoimentos nos revela que aos olhos dos profissionais de saúde, assistir o morrer do paciente se mostra como:

\subsection{Uma sensação de frustração, tristeza e perda}

Os fragmentos dos depoimentos revelam que os profissionais de saúde, ao assistirem o morrer dos pacientes, ficam frustrados tendo uma sensação de tristeza, lamentando a perda daquele alguém com quem se acostumaram a conviver. Podemos constatar esta percepção nas seguintes falas:

João:* Ao iniciar a carreira ... a morte ... significava um sentimento forte de incapacidade, frustração e culpa. Com o passar de tempo ... a idéia de culpa e incapacidade foram se dissipando. Porém, o sentimento de tristeza e perda de alguém ainda bate forte em nosso ser...

\section{Ana: Uma grande frustração.}

José: A função precipua da equipe de saúde em geral, e do médico em particular, é salvar vidas. A morte de um paciente significa para ele o fim, e para mim, uma perda total...

A sensação de frustração citada pelos profissionais está relacionada com o fato de que são preparados para salvar vidas. A preservação e o prolongamento da vida é o objetivo destes profissionais, por conseguinte, sentem-se incapazes ou frustrados quando não obtêm êxito em suas tentativas. Por outro lado, a convivência diária, às vezes, por tempo prolongado com os pacientes, gera um certo envolvimento, especialmente nos profissionais de enfermagem que acabam por sentir tristeza e uma sensação de vazio quando estes morrem.

\subsection{Interpretada de maneira distinta conforme a idade, diagnóstico e prognóstico do paciente}

Os participantes da pesquisa revelaram que sentem o morrer dos pacientes de maneira diferenciada, interferindo diretamente sobre estes sentimentos a idade, o diagnóstico e o prognóstico dos mesmos. Podemos perceber esta conotação nos discursos que se seguem:

Bruna: ...de acordo com a idade, o pesar é maior ou menor. Quando jovem, adolescente, com tristeza que a morte está vindo cedo. Os velhos, que chegou a hora pois já viveram muito...

Roberto: Depende de vários fatores tais como: idade do paciente, prognóstico da doença, período da assistência etc...

Luis: ...é frustrante perder-se um paciente viável ao passo que é um alívio perder-se um paciente terminal...

Vera: ...existem algumas patologias que o morrer deste paciente significa descanso, alívio, menos sofrimento, diminuição da dor...

$O$ freqüente assistir ao morrer dos pacientes desencadeia os mecanismos revelados nesta unidade de significação, ou seja, a tentativa de racionalizar ou esquematizar comportamentos e sentimentos conforme a classificação da perda. Como estes momentos são vivenciados diversas vezes, o desgaste destes profissionais é muito intenso, por isso é necessário instituir alguma estratégia para diminuir o impacto. Decorrente deste mecanismo de defesa, alguns profissionais verbalizaram que de acordo com a idade, o diagnóstico e o prognóstico sentem de maneira diferente, isto é, podem controlar seus sentimentos. A relevância que recebe na formação dos profissionais da área de saúde o controle das emoções no tocante à temática da morte,

Os nomes dos depoentes sâo fictícios. 
tem sido revista, ultimamente, nos currículos das escolas, visando uma adequação para melhor prepará-los para este enfrentamento, já que conviverão em seu dia-a-dia com esta problemática. Também, porque começa a ser difundida a idéia de que a finitude humana é uma condição básica que deve ser trabalhada entre os homens, conforme salienta BOEMER(4).

\subsection{Um momento difícil, de impotência e estresse para os profissionais}

O morrer dos pacientes é percebido pelos profissionais de saúde como um momento dificil, gerando impotência e estresse, como pode ser observado nos relatos que se seguem:

Thais: Apesar de tentar encarar a morte de um paciente como uma coisa normal, é para mim muito dificil, pois cada paciente que morre me deixa com uma sensação de impotência muito grande...

Roberto: ...todo obito envolve uma série de fatores estressantes para o profissional de saúde. Além de todos os cuidados pré-morte, temos ainda a assistência à família, sem citar os cuidados ao ambiente.

Maria: Sendo eu uma profissional de saúde... tendo contato direto e constante com o paciente, ainda não consegui aceitar a morte como algo natural da vida. Considero a morte o momento mais dificil para o ser humano... a morte toca-me profundamente... é uma perda sem retorno.

A participação dos profissionais de saúde no morrer dos pacientes afeta-os diretamente $e$ esta vivência desperta-lhes os mais diversos sentimentos. A sensação de impotência surge decorrente de sua própria formação, ou seja, foram preparados para manter e recuperar a vida. Ao perceberem que estão perdendo o controle sobre a vida dos pacientes e que não conseguem preservá-la, sentem-se deprimidos e impotentes. A tentativa frustrada de manutenção da vida através da utilização dos recursos tecnológicos, acaba provocando o estresse em razão da responsabilidade que assumem perante a sociedade e, desta forma, a habilidade profissional estará, de certa forma, sendo testada. Por isso, a expressão momento dificil, revelada pelos profissionais, é a sensação de que, neste instante, necessitam dominar seus próprios sentimentos já que, certamente, sua capacidade profissional estará em evidência. Sobre este aspecto SANTOS(12), tratando do enfrentamento e negação da morte dos profissionais de saúde, afirma que os sentimentos mais comuns frente à morte são impotência, culpa e raiva, vividos com muita dor. Prossegue dizendo que o médico não acredita, inicialmente, que seu paciente tenha morrido, ficando aborrecido por tal fato ter ocorrido, apesar de todos os seus esforços. Alguns, complementa, após refletirem sobre o que mais poderiam ter feito, e não verificando falhas em seu desempenho, aceitam a a morte como um fato inevitável. A morte, entretanto, é negada pelos profissionais, em todos os niveis, até mesmo na forma de expressão, sendo comum dizer que o paciente foi a óbito ou teve parada cardíaca.

Por outro lado, não devemos esquecer também que a participação dos familiares na morte do doente é outro momento de tensão e constrangimento, já que fica previamente estabelecida uma relação de confiança para com os profissionais, com a intemação de um doente.

\subsection{Faz parte do cotidiano dos profissio- nais de saúde, sendo esta uma con- vivência natural}

Se por um lado a morte é percebida pelos profissionais de saúde como um momento difícil, de frustração e tristeza, por outro acaba fazendo parte do cotidiano destes, sendo encarada com naturalidade. Os discursos que se seguem evidenciam este pensamento:

Nina: Eu costumo encarar a morte como coisa muito natural. O que, às vezes, me choca é a forma como se morre... Porém não sou de ficar lamentando, é coisa que logo passa. Procuro superar, pois se ficarmos levando tudo muito a sério... isso acaba prejudicando a saúde e o andamento do trabalho..

Sonia: No tempo em que eu nåo convivia com a morte, ela me assustava, me deprimia. Depois de vivenciartantas mortes... é um fato que nåo me abala como antes...

Anita: Creio que com o tempo a morte choca de maneira diferente o profissional.

Fernando: No contexto de algumas experiên- 
cias, resultou que a morte so se toma diferente para o profissional de saúde porque faz parte do seu dia-a-dia e não se tem altemativas como se espera.

Nota-se nesses depoimentos que o convívio quase que diário com o morrer dos pacientes afeta aos profissionais, sendo percebido de maneira diferenciada entre os mais antigos e os mais jovens.

Fica claro que, com o passar do tempo, acabam por criar um mecanismo que os auxilia neste enfrentamento. Não devemos esquecer também que de certa maneira, o distanciamento observado pelos profissionais nestes momentos, pode estar relacionado com o envolvimento existente entre eles, uma vez que o sistema hospitalar no qual estão inseridos muitas vezes interfere no relacionamento entre os profissionais e destes para com os pacientes. A este

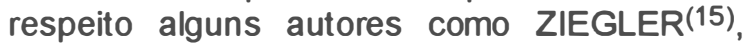
$\operatorname{LUZ}^{(6)}$, MALDONADO(7), ao tratarem da questão dos pacientes hospitalizados, revelam que estes enfrentam momentos de solidão e abandono, deixando de ser um homem para ser uma doença, perdendo a identidade de cidadão. Ao perceberem que o paciente morrerá, mantêm um jogo de aparências, falando por meias palavras, omitindo ou distorcendo a verdade e assim, acabam isolando-o, não permitindo que exteriorizem seus sentimentos.

Assim, esta aparente aceitação do morrer como parte da profissão não deixa de ser uma indicação da falta de preparo dos profissionais para estas ocasiões, pois ao presenciarmos o morrer dos outros acabamos por lembrar da finitude humana.

\subsection{Sensação de culpa e falha na as- sistência prestada}

Os profissionais de saúde participam do morrer dos paciente questionando sua atuação. Algumas vezes, sentem-se culpados, acreditando que falharam na prestação da assistência, como mostram os depoimentos que se seguem:

Melissa: A morte, para mim, na atual situação é normal, mas quando se trata de um paciente ao qual eu me apegue eu me sinto até culpada, achado que se eu desse mais atenção nåo aconteceria dele falecer.
Thaís: ...apesarde achar que fiz tudo para evitar o obito, sempre fica a sensação de ter sido pouco o que eu fiz...

Decorrentes de toda uma formação, os profissionais de saúde são preparados para a manutenção, preservação e recuperação da vida. Foram treinados para tal. O morrer, nesta conjuntura, aparece como fracasso, ou seja, falharam tecnicamente. Não obtiveram êxito em suas tentativas e, portanto, neste momento, a competência profissional está sendo testada, por isso a sensação de culpa. Sentem-se culpados porque acreditam que falharam e não utilizaram todas as alternativas para recuperarem a vida do paciente. Questionam a conduta terapêutica e que outros recursos poderiam ter utilizado para manter o paciente vivo. Nesta análise da situação passam por momentos de angústia, dúvida, raiva e, sem outra alternativa, acabam por aceitar o fato.

\subsection{Um oponente que contraria seus propósitos (salvar vidas)}

A morte é percebida pelos profissionais de saúde como um inimigo que contraria seus propósitos, salvar vidas, derrotando-os. Os discursos que se seguem evidenciam este pensar:

Leonardo: Já li ou ouvi dizer ...que o profissional de saúde nunca deve se acostumar com a morte. Ele deve sempre lutar contra ela, ou seja, ser o seu eterno adversário...

José: A clara demonstração das limitaçőes da minha profissão (como médico), da medicina (como ciência) e da pessoa humana me traz a angústia da necessidade de diminuir essas limitaçסes e, quem sabe?, evoluir.

Bruna: ...como profissional de enfermagem e como pessoa jamais aceitarei a morte, porque é contra ela que eu luto todos os dias, e o dia que eu me acostumar com a morte, não senvirei mais para ser enfermeira...

Pelas descrições, nota-se que a morte é visualizada pelos profissionais como um momento de derrota. É como se travassem uma luta imaginária e quando o paciente morre, significa que perderam a batalha. Em suas falas deixam clara a intenção de serem os etemos adversários da morte, refletindo quanto às limitações de suas profissões, externando que se aceitarem o 
morrer com naturalidade, significa que não mais estarão aptos a exercerem suas profissões.

Mais uma vez, a formação destes profissionais atua diretamente sobre este pensar. Foram preparados para salvar vidas, vê-la escapando de seu controle é sinônimo de fracasso, de derrota, em outras palavras - de falência profissional.

\subsection{Um momento de reflexão que Ihes lembra a finitude humana}

O convívio contínuo com o morrer dos pacientes faz com que os profissionais reflitam sobre a finitude humana, como observamos nos depoimentos a seguir.

Eduardo: ...para mim, falar da morte de um paciente é lembrar futuramente a minha propria morte.

Leonardo: ...em todas as mortes assistidas por mim, medito e chego à obvia conclusåo: todos chegaremos a este momento.

Carolina: Estamos sempre procurando evitar conversar sobre este assunto, mas não podemos nos esquecer de que a morte é inevitável..

Como revelam estes discursos, o assistir ao morrer dos pacientes conduz os profissionais à meditação, refletindo em relação à finitude humana. Apesar de disporem de vários recursos tecnológicos que permitem o prolongamento da vida biofisiológica do doente para além do instante em que se extingue a nítida consciência de sua existência, no momento em que a morte chega, percebem não ter o que fazer para impedir sua chegada, despem a couraça de detentores do poder, rendendo-se às evidências, ou seja, da finitude humana. Em muitos momentos, tão envolvidos que estão em suas funções, insistem nas manobras de ressuscitação porque não aceitam o fato do paciente ter morrido, apesar de todo o seu empenho. Nestes momentos, após aceitarem o fato do morrer, ficam pensativos, refletindo sobre a condição humana de que somos finitos. A finitude constitui, portanto, 0 problema central da existência humana, já que não somos etemos. Um dia, tudo acaba e o vivenciar o morrer dos outros acaba por lembrarnos a nossa própria finitude.

\subsection{Uma melhor aceitação quando ampara- dos por crenças religiosas}

Os profissionais de saúde, em seus depoimentos, revelaram que acreditam na força de um ser superior e, desta forma, conseguem suportar melhor o morrer dos pacientes, como demonstram os discursos que se seguem:

Mário: ...toma-se mais fácil de aceitar tal fato, principalmente quando se acredita que esta vida é apenas uma passagem para evolução de outras vidas.

Thaís: ... acredito numa outra vida apos a morte, logo tento encarar que chegou o momento do paciente e a sensação de impotência tende a diminuir.

Yasmin: ...em todos os casos, por formação religiosa, com certeza é a vontade suprema de Deus.

Os profissionais de saúde, como seres humanos que são, procuram se apoiar em crenças religiosas para aceitar melhor a perda dos pacientes. Nota-se que, de uma maneira geral, quando as pessoas possuem alguma crença, costumam suportar melhor perdas, saindo fortalecidas destes momentos de crise. Assim, também quando os profissionais de saúde acreditam na vontade de um ser superior, compreendem e tendem a aceitar melhor o morrer dos pacientes já que o relacionam à vontade suprema, ou seja, que chegou o seu momento. Entretanto, não deixam de, num momento inicial, questionar a sua competência profissional e atuação diante daquele paciente, fazem um exame de consciência e, por fim, rendem-se às evidências; entretanto, buscam num ser supremo a justificativa para aquele desfecho e acabam por aceitá-lo.

Desta forma, os valores culturais inerentes a cada pessoa, atuam como elementos de amparo e conforto $\mathrm{p}$ ara os profissionais de saúde, sendo importantes na sua reestruturação e possibilitando a compreensão do morrer como parte integrante da existência humana.

\section{CONSIDERAÇÕES FINAIS}

A morte é um desafio que ameaça os homens desde o começo dos séculos. Através de uma longa trajetória, foi assumindo conotações 
distintas, sendo percebida conforme as idéias dos homens de cada época.

Nos dias atuais, doença e morte, graças à modernidade e às mudanças que se processaram na sociedade, passaram a ocupar os hospitais deixando os lares, como outrora. Ao ocupar os hospitais, a morte passa a ser vivenciada por outras pessoas, além dos familiares, e a fazer parte do cotidiano dos profissionais de saúde.

O contato freqüente com a morte conduz estas pessoas a refletirem, passando a questionar seus propósitos, como o de salvar vidas, e possibilitando o enfrentamento do assistir ao morrer do outro, lembrando-Ihes a condição humana de finitude.

Os valores culturais individuais destes profissionais atuam no seu pensar, sendo distinta a conotação para aqueles que se apoiam em alguma crença religiosa. Estes visualizam com mais aceitação, percebendo as limitações de sua condição humana e acreditando na força de um ser supremo. Por outro lado, com esta crença, amenizam a sensação de culpa e perda que perpassa nestas ocasiões, já que foram preparados para a preservação e recuperação da vida. No entender de BOEMER(4), a situação é problemática para os profissionais pois não se deve esquecer que na realidade, fica difícil manter o paciente vivo a todo custo e, simultaneamente, ajudá-lo a morrer de forma digna.

Os profissionais de saúde, em sua maioria, ficam preocupados e presos a detalhes técnicos, certamente porque isto faz com que se sintam competentes dando uma resposta técnica e objetiva. Todavia, a assistência ao morrer dos pacientes implica em envolvimento, conhecimento sobre as pessoas e manifestações frente ao viver e ao morrer(11).

É importante ressaltar que como os profissionais de saúde são preparados para a manutenção da vida, sentem dificuldade na aceitação do morrer porque este revela-Ihes a condição da finitude humana. Preparar-se para a própria morte significa conhecer-se a si próprio uma vez que, para os profissionais, a possibilidade da morte é percebida, mas não de forma clara. Surge como eventualidade e não como algo esperado, já que se sentem compromissados com a vida e é em sua preservação que se sentem gratificados $(4)$.

Na verdade, nós - profissionais de saúde que lidamos com o morrer dos pacientes, devemos incluir a perspectiva da morte na vida para darmos conta da própria finitude, já que a morte é um processo natural da existência humana com o qual temos de aprender a conviver. Assim, a compreensão da morte como possibilidade inseparável da vida do homem, enquanto ser-no-mundo, pode constituir-se num momento rico de reflexões para os profissionais de saúde, auxiliando-os no cuidar dos pacientes e permitindo um enfrentamento deste instante com maior amplitude.

\section{REFERÊNCIAS BIBLIOGRÁFICAS}

1. ARIĖS, Philippe. O homem diante da morte. Trad. Luiza Ribeiro, 2. ed., Rio de Janeiro: Francisco Alves, 1989. v.1, p.103-310, $2^{\mathrm{a}}$ parte

$2 . \quad$ História da morte no Ocidente - da Idade Média aos nossos dias. Trad. Priscila Vianna de Siqueira. Rio de Janeiro: Francisco Alves, 1977, 2 parte, p.67-80, cap. VI.

3. BOEMER, M.R. O fenómeno morte: o pensar, o conviver e o educar. 1989, 111p. Tese (Livre Docéncia), Esc. Enf. Ribeirăo Preto, USP, Såo Paulo, 1989.

4. BOEMER, M.R. et al. A idéia de morte em unidade de terapia intensiva - análise de depoimentos. Rev. Gaúcha Enf., Porto Alegre, v.10, n.2, p.8-14, jul. 1989.

5. KASTENBAUM, R. e AISEMBERG, R. Psicologia da Morte. Trad. Adelaide P. Lessa. Săo Paulo: EDUSP, 1983, $1^{2}$ parte. p.149-189, cap. VI.

6. LUZ, M.T. Estratégia de hegemonia e análise política de instituiçðes. In: As Instituições médicas no Brasil. Rio de Janeiro: Graal, 1986, cap 1, p.23-45.
7. MALDONDO, M.T. O médico e a cliente próxima da morte. Trabalho apresentado no XII Congresso Brasileiro de Ginecologia e Obstetrícia. Salvador, novembro, 1978 (mimeo).

8. MARTINS, J. e BICUDO, M.A.V. A pesquisa qualitativa em Psicologia. Fundamentos e Recursos Básicos. Såo Paulo: Moraes/EDUC, 1989. 110p.

9. MARTINS, J. et al. A fenomenologia como alternativa metodológica para a pesquisa - algumas consideraçठеs. Rev. Esc. Enf. USP. n.24, p.139-147, 1990.

10. PITTA, A. Hospital - dor e morte como oflcio. 2. ed. Săo Paulo: Hucitec, 1991, p.25-79, cap. 1.

11. REZENDE, A.L.M. et al. Ritos de morte na lembrança de velhos. Projeto de pesquisa em fase de desenvolvimento na Universidade Federal de Belo Horizonte. 1991 (mimeo).

12. SANTOS, C.A.F. Os profissionais de saúde enfrentamnegam a morte. In: MARTINS, J.S. A morte e os mortos na sociedade brasileira. Såo Paulo: Hucitec, 1983. p.15-24, cap 1 
13. SPINDOLA, T. e PINHEIRO, M.T. A morte e a sociedade. Trabalho apresentado no Encontro "Repensando a Primeira Década do Mestrado da UNI-RIO". Rio de Janeiro, 1992 (mimeo).

14. SPÍNDOLA, T. O CTI sob a ótica das pessoas de enfermagem. Uma abordagem fenomenológica. Rio de Janeiro, 1992, 102p. Dissertaçăo (Mestrado), Escola de Enfermagem Alfredo Pinto, UNI-RIO. 1992.
15. ZIEGLER, J. Os vivos e a morte. Trad. Aurea Weissenberg, Rio de Janeiro: Zahar Editores, 1977, p.241254, cap IV

Recebido para publicaçăo em 18.03.94 